\title{
Improving production of extracellular proteases by random mutagenesis and biochemical characterization of a serine protease in Bacillus subtilis $\mathrm{S1-4}$
}

\author{
X.C. Wang, H.Y. Zhao, G. Liu, X.J. Cheng and H. Feng \\ Sichuan Key Laboratory of Molecular Biology and Biotechnology, \\ The Key Laboratory for Bio-Resources and the Eco-Environment of Ministry \\ of Education, College of Life Sciences, Sichuan University, Chengdu, China \\ Corresponding author: H. Feng \\ E-mail: hfeng@scu.edu.cn
}

Genet. Mol. Res. 15 (2): gmr.15027831

Received October 15, 2015

Accepted December 23, 2015

Published June 17, 2016

DOI http://dx.doi.org/10.4238/gmr.15027831

\begin{abstract}
The feather is a valuable by-product with a huge annual yield produced by the poultry industry. Degradation of feathers by microorganisms is a prerequisite to utilize this insoluble protein resource. To improve the degrading efficiency of feathers, mutagenesis of the bacterium Bacillus subtilis S1-4 was performed. By combining ultraviolet irradiation and N-methyl-N'-nitro-N-nitrosoguanidine treatment for mutagenesis, a high protease-producing mutant (UMU4) of B. subtilis S1-4 was selected, which exhibited 2.5 -fold higher extracellular caseinolytic activity than did the wild-type strain. UMU4 degraded chicken feathers more efficiently, particularly for the release of soluble proteins from the feathers, compared to the wild-type strain. Furthermore, an extracellular protease with a molecular weight of $45 \mathrm{kDa}$, as determined by SDSPAGE, was purified from UMU4. Biochemical characterization indicated that the caseinolytic activity of the protease was largely inhibited by phenylmethanesulfonyl fluoride, suggesting that the purified enzyme is
\end{abstract}


a serine protease. This protease was highly active over a wide range of pHs (6.0 to 12.0) and temperatures $\left(50^{\circ}\right.$ to $\left.75^{\circ} \mathrm{C}\right)$ with an optimal $\mathrm{pH}$ and temperature of 8.0 and $65^{\circ} \mathrm{C}$, respectively. The purified enzyme exhibited good thermostability with a $72.2 \mathrm{~min}$ half-life of thermal denaturation at $60^{\circ} \mathrm{C}$. In addition, this protease was not sensitive to heavy metal ions, surfactants, or oxidative reagents. In conclusion, strain improvement for protease production can serve as an alternative strategy to promote feather degradation. The UMU4 mutant of $B$. subtilis and its serine protease could be potentially used in various industries.

Key words: Bacillus subtilis; Mutagenesis; Strain improvement; Purification; Serine protease

\section{INTRODUCTION}

Proteases are widely found in many species of animals, plants and microorganisms, and have been intensively studied by various methods, including protein engineering, molecular structure, and catalytic kinetics and mechanisms (Rao et al., 1998; Bryan, 2000; Polgár, 2005). Over the past several years, there has been an increase in the application of proteases in various industries, such as detergent additives, food and feed processing, pharmaceutical, and leather and silk processing (Gupta et al., 2002). Microorganisms are an important source of proteases due to their fast growth, simple fermentation conditions, special metabolic processes, and wide distribution. A large proportion of commercial proteases are produced by microorganisms, particularly Bacillus strains (Kumar and Takagi, 1999; Gupta et al., 2002).

Typically, strains of microorganisms isolated from natural niches cannot be directly used in the industrial-scale production of proteases due to their lower yield. To meet the evergrowing demand of proteases, many high protease-producing strains have been selected for industrial production. For example, a hyper-producing mutant of Bacillus clausii KSM-K16 was developed and used for production of M-protease at an industrial scale (Saeki et al., 2007). Various technologies have been exploited for this purpose (Rowlands, 1984; Vinci and Byng, 1999; Parekh et al., 2000; Li et al., 2011). Classic mutation or selection techniques like ultraviolet (UV) irradiation and chemical treatment are still used today. For example, protease activity was increased by about 4-fold in Bacillus stearothermophilus by chemical mutagenesis (Zamost et al., 1990).

Previously, a strain of Bacillus subtilis S1-4 with the capacity to degrade feathers efficiently was isolated from chicken feathers, as it was able to secrete several proteases with hydrolytic activity to various substrates like casein, gelatin, and keratin (Yong et al., 2013). In order to obtain a high protease-producing strain, multiple rounds of mutagenesis by UV and chemical treatment were applied to B. subtilis $\mathrm{S} 1-4$, and a serine protease was purified from the mutated isolate (UMU4) and its catalytic properties were characterized.

\section{MATERIAL AND METHODS}

\section{Microorganisms and growing media}

B. subtilis S1-4 was isolated from the waste chicken feathers from a local poultry farm 
in China (Yong et al., 2013) and maintained on Luria-Bertani (LB; $1 \%$ peptone, $0.5 \%$ yeast, $0.5 \% \mathrm{NaCl}$ ) agar plates. Minimal media (MM; $0.15 \% \mathrm{~K}_{2} \mathrm{HPO}_{4}, 0.0025 \% \mathrm{CaCl}_{2}, 0.0015 \%$ $\left.\mathrm{FeSO}_{4} \cdot 7 \mathrm{H}_{2} \mathrm{O}, 0.0005 \% \mathrm{ZnSO}_{4} \cdot 7 \mathrm{H}_{2} \mathrm{O}, 0.0025 \% \mathrm{MgSO}_{4} \cdot 7 \mathrm{H}_{2} \mathrm{O}\right)$ was used to formulate the milk-containing medium (MM plus 1\% milk), feather medium (MM plus 5\% chopped chicken feathers), and the fermentation medium (MM plus 3\% soluble starch, $0.2 \%$ yeast extract, and $0.5 \%$ gelatin) for various purposes.

\section{Mutagenesis and selection of mutants}

For UV mutagenesis, B. subtilis S1-4 was first incubated in LB broth at $37^{\circ} \mathrm{C}$ for $16-$ $18 \mathrm{~h}$. After collection by centrifugation at $4,600 \mathrm{~g}$, the cells were washed with sterilized water and re-suspended in PBS buffer, $\mathrm{pH} 7.2\left(135 \mathrm{mM} \mathrm{NaCl}, 2.7 \mathrm{mM} \mathrm{KCl}, 1.5 \mathrm{mM} \mathrm{KH}_{2} \mathrm{PO}_{4}, 8 \mathrm{mM}\right.$ $\mathrm{K}_{2} \mathrm{HPO}_{4}$ ), at a density of about $10^{6}$ cells $/ \mathrm{mL}$. Then, $5 \mathrm{~mL}$ bacterial suspension was dispensed into a $9 \mathrm{~cm}$-diameter Petri dish and subjected to irradiation by UV under the indicated energy in the UV Crosslinker (Amersham Biosciences, Madison, USA) in the dark. The treated cells were diluted appropriately and spread on milk-containing MM agar plates. The plates were incubated at $37^{\circ} \mathrm{C}$ in the dark for $48 \mathrm{~h}$. The hydrolytic halos around the mutated colonies were measured and compared against the halo of the wild-type strain. Simultaneously, the colonies with larger transparent hydrolytic halos in diameter were selected. The selected colonies were sub-cultured by streaking on the same agar plates several times until the hydrolytic halo formed stably.

The mutant isolate (UV3), which was obtained from the first UV mutagenesis, was subjected to chemical mutagenesis again. UV3 was grown in LB broth at $37^{\circ} \mathrm{C}$ for $16-18 \mathrm{~h}$ and the cells were collected by centrifugation. The resultant cell suspension (about $10^{6}$ per $\mathrm{mL}$ ) was treated with N-methyl-N'-nitro-N-nitrosoguanidine (MNNG) solution $(1.0 \mathrm{mg} / \mathrm{mL}$ final concentration) for $0.5 \mathrm{~h}$, and then washed with sterilized water twice by centrifugation at $4,600 \mathrm{~g}$. The cells were diluted appropriately and spread on milk-containing MM plates. After incubation at $37^{\circ} \mathrm{C}$ for $24-48 \mathrm{~h}$, the colonies were selected based on size of the transparent hydrolytic halos and streaked on the same agar plates. A mutant isolate (MG5) was selected after chemical mutagenesis and subjected to a second UV mutagenesis as described above. Finally, the mutant isolate UMU4 was obtained.

Next, the selected mutant isolates were inoculated into $20 \mathrm{~mL}$ fermentation medium and cultured at $37^{\circ} \mathrm{C}$ for $48 \mathrm{~h}$ with shaking at $180 \mathrm{rpm}$. The supernatant from each culture was used to determine the extracellular protease activity following a protocol described previously (Wan et al., 2009). The mutant isolates were applied to $100 \mathrm{~mL}$ feather medium to assess degradation capability. The cultures were incubated at $37^{\circ} \mathrm{C}$ for $72 \mathrm{~h}$ with shaking at $180 \mathrm{rpm}$. At the end of fermentation, the cultures were filtered through four layers of gauze cloth to remove debris, which was dried and used to calculate feather degradation. The supernatant was further clarified by centrifugation at $15,500 \mathrm{~g}$ and then used to determine the content of soluble proteins, oligopeptides, and free amino acids as described previously (Yong et al., 2013). All experiments were performed in triplicate.

\section{Purification of the serine protease}

For purification of the extracellular protease, the mutated isolate (UMU4) of B. subtilis S1-4 was inoculated in $1.0 \mathrm{~L}$ fermentation medium in a 3-L Erlenmeyer flask and incubated at $37^{\circ} \mathrm{C}$ with shaking at $180 \mathrm{rpm}$ for $48 \mathrm{~h}$. The culture was clarified by centrifugation at 4,600 $\mathrm{g}$ 
at $4{ }^{\circ} \mathrm{C}$. The resulting supernatant was precipitated by the addition of solid ammonium sulfate at $60 \%$ saturation. The pellet was collected by centrifugation at $15,500 \mathrm{~g} \mathrm{rpm}$ for $10 \mathrm{~min}$ at $4{ }^{\circ} \mathrm{C}$ and then solubilized in $5 \mathrm{~mL} 20 \mathrm{mM}$ Tris- $\mathrm{HCl}\left(\mathrm{pH} \mathrm{8.0)}\right.$ plus $1 \mathrm{M}\left(\mathrm{NH}_{4}\right)_{2} \mathrm{SO}_{4}$. After clarification by centrifugation and filtration through a $0.45 \mathrm{~mm}$-diameter filter, the resulting sample was applied to a hydrophobic column $(0.8 \times 15 \mathrm{~cm})$ pre-equilibrated with buffer A $(20$ $\mathrm{mM}$ Tris-HCl, $\left.1 \mathrm{M}\left(\mathrm{NH}_{4}\right)_{2} \mathrm{SO}_{4}, \mathrm{pH} 8.0\right)$. The proteins were eluted with a linear gradient [1 to $0 \mathrm{M}\left(\mathrm{NH}_{4}\right)_{2} \mathrm{SO}_{4}$ ] at a flow rate of $1 \mathrm{~mL} / \mathrm{min}$ on the ÄKTA Purifier System (GE Healthcare, Wisconsin, USA). The 2-mL fractions with protease activity were pooled and dialyzed in phosphate buffer $(25 \mathrm{mM}, \mathrm{pH} 8.0)$ overnight at $4^{\circ} \mathrm{C}$.

The dialyzed sample (about $3 \mathrm{~mL}$ ) was loaded on the Sephacryl S-200 column $(0.4 \times 60$ $\mathrm{cm}$, GE Healthcare, Wisconsin, USA) pre-equilibrated with $25 \mathrm{mM}$ phosphate buffer $(\mathrm{pH} 8.0)$ and then eluted with the same buffer at a flow rate of $0.5 \mathrm{~mL} / \mathrm{min}$. The $1-\mathrm{mL}$ fractions with protease activity were pooled. The protease sample was stored in storage buffer, $\mathrm{pH} 8.0(25 \mathrm{mM}$ phosphate, $50 \%$ glycerol, $1 \mathrm{mM} \mathrm{CaCl}_{2}$ ). Finally, the purified protease was analyzed by $12.5 \%$ SDS-PAGE and subjected to zymogram analysis with casein as the substrate (Cedrola et al., 2012).

\section{Characterization of the purified protease}

Hydrolytic activity of the protease towards the substrate casein was assayed as described previously (Wan et al., 2009). A standard assay for the caseinolytic reaction was set up in $400 \mu \mathrm{L}$ borate- $\mathrm{NaOH}$ buffer, $\mathrm{pH} \mathrm{9.6,} \mathrm{containing} 5 \mathrm{mg}$ enzyme and $4 \mathrm{mg}$ casein as substrate, and then incubated in a $60^{\circ} \mathrm{C}$ water bath for exactly 10 min.

To determine the effects of $\mathrm{pH}$ and temperature on the hydrolytic activity, the activity assay was performed at different temperatures $\left(40^{\circ}, 50^{\circ}, 60^{\circ}, 65^{\circ}, 70^{\circ}, 75^{\circ}\right.$, or $\left.80^{\circ} \mathrm{C}\right)$ and different $\mathrm{pHs}(3,4,5,6,7,8,9,10,11,12$, or 13$)$. In addition, thermostability of the protease was also determined by measuring the residual hydrolytic activity after pre-incubating the enzyme solution at $50^{\circ}, 60^{\circ}, 65^{\circ}$, or $70^{\circ} \mathrm{C}$ for the indicated time in the presence of $2 \mathrm{mM} \mathrm{CaCl}_{2}$. Finally, the effect of various chemicals on the catalytic reaction was analyzed. We examined the effect of $\mathrm{NaCl}$ concentrations $(0,50,100,200$, or $500 \mathrm{mM}), 2 \mathrm{mM}$ various divalent metal ions $\left(\mathrm{Mg}^{2+}, \mathrm{Ca}^{2+}, \mathrm{Mn}^{2+}, \mathrm{Ni}^{2+}, \mathrm{Cu}^{2+}\right.$, or $\left.\mathrm{Zn}^{2+}\right), 5 \mathrm{mM}$ surfactants and organic solvents, and 5 $\mathrm{mM}$ protease inhibitors (Tween-20, Triton X-100, sodium dodecyl sulfate (SDS), dimethyl sulfoxide (DMSO), $\mathrm{Na}_{2} \mathrm{SO}_{3}, \beta$-mercaptoethanol ( $\beta$-2ME), ethylene bis(oxyethylenenitrilo)tetra-acetic acid (EGTA), or phenylmethanesulfonyl fluoride (PMSF)). All activity assays were performed in triplicate.

\section{RESULTS}

\section{Mutagenesis and selection of mutant isolate}

With $B$. subtilis S1-4 as the starting (parent/wild-type) strain, UV irradiation was first applied to the bacterial cells at an energy level of $100 \mathrm{E}\left(\mathrm{E}=100 \times 9^{2} \mu \mathrm{J} / \mathrm{cm}^{2}\right)$, which resulted in a $99 \%$ mortality rate. In total, more than 60,000 surviving colonies were screened after the first mutagenesis. On the milk-containing agar plates, the treated cells formed colonies with various sizes of hydrolytic halos (Figure 1A). Finally, several isolates with stable and larger halos were selected after successively streaking them on the agar plates several times (Figure 1B). As a result, an isolate that we termed UV3 was obtained. 

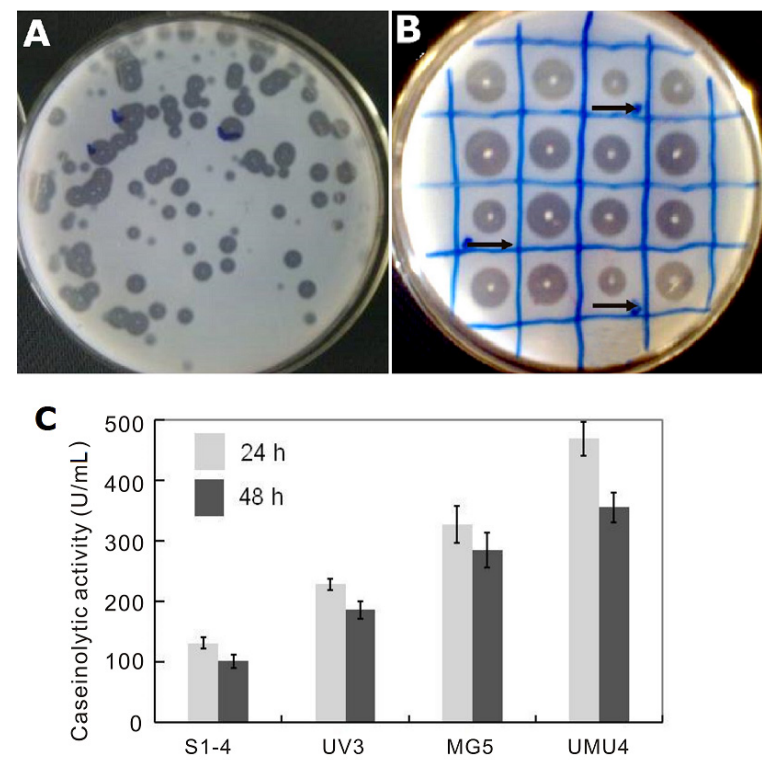

Figure 1. Mutagenesis and screening of mutant isolates of Bacillus subtilis S1-4 with improved protease activity. A. A representative milk-containing agar plate with bacterial cells after UV irradiation. B. Comparison of hydrolytic halos on the milk-containing agar plate of the selected mutant isolates and the wild-type strain (indicated by an arrow) of $B$. subtilis S1-4. C. Comparison of protease production in fermentation broth with the selected mutant isolates and the wild-type strain of B. subtilis S1-4.

At the second mutagenesis, $1 \mathrm{mg} / \mathrm{mL}$ MNNG was applied to the UV3 cells, which resulted in a $98.5 \%$ mortality rate. After spreading on the milk-containing agar plates, one isolate (MG5) was selected out of the 57,500 surviving colonies. Finally, the third mutagenesis was performed with UV irradiation with MG5 as the starting strain, and one isolate (UMU4) was selected from about 50,000 surviving colonies.

To confirm the selected isolates had improved caseinolytic activity, three isolates (UV3, MG5 and UMU4) were inoculated in $20 \mathrm{~mL}$ fermentation medium and cultured at $37^{\circ} \mathrm{C}$. The extracellular protease activity was determined for these cultures at 24 and $48 \mathrm{~h}$, respectively. The results are presented in Figure 1C. The isolate UMU4 achieved a hydrolytic activity up to $469 \mathrm{U} / \mathrm{mL}$ at $24 \mathrm{~h}$, an increase of about 2.5 -fold compared to the wild-type strain $(131 \mathrm{U} / \mathrm{mL})$. The other isolates (UV3, MG5) also showed higher protease activity than the wild-type strain S1-4.

The wild-type strain S1-4 and two isolates (MG5 and UMU4) were chosen to further evaluate their ability to degrade feather. All three strains were inoculated into $100 \mathrm{~mL}$ feather medium and incubated at $37^{\circ} \mathrm{C}$ for $72 \mathrm{~h}$. After fermentation, the extracellular protease activity, content of soluble proteins, oligopeptides and free amino acids, and weight loss of feather in the fermentation broth were determined (Table 1). Specifically, the caseinolytic activity of isolate UMU4 approached $302.40 \mathrm{U} / \mathrm{mL}$, which was much higher than that of the wild-type strain $(50.40 \mathrm{U} / \mathrm{mL})$. In comparison with the parent strain S1-4, soluble protein content and weight loss of the feather for the mutant UMU4 were obviously increased. Additionally, the contents of oligopeptides and free amino acids were enhanced. These results indicate that extracellular protease activity results in the degradation of chicken feather. 
Table 1. Degradation of chicken feather by the mutant isolates and wild-type strain of B. subtilis S1-4*.

\begin{tabular}{l|c|c|c}
\hline Isolates & S1-4 & MG5 & UMU4 \\
\hline Protease activity $(\mathrm{U} / \mathrm{mL})$ & $50.40 \pm 1.9$ & $152.69 \pm 37.2$ & $302.40 \pm 31.4$ \\
\hline Soluble proteins $(\mathrm{mg} / \mathrm{mL})$ & $13.96 \pm 3.8$ & $15.71 \pm 1.9$ & $24.03 \pm 1.3$ \\
\hline Oligopeptides $(\mathrm{mg} / \mathrm{mL})$ & $7.46 \pm 0.7$ & $5.55 \pm 0.8$ & $8.91 \pm 1.0$ \\
\hline Amino acids $(\mathrm{mg} / \mathrm{mL})$ & $4.47 \pm 0.3$ & $4.23 \pm 0.3$ & $4.73 \pm 0.4$ \\
\hline Degraded feather $(\mathrm{g})$ & $2.34 \pm 0.2$ & $3.93 \pm 0.3$ & $4.43 \pm 0.3$
\end{tabular}

*Data are reported as means \pm SD derived from experiments performed in triplicate.

\section{Purification and characterization of the protease from mutant UMU4}

The protease from the fermentation broth of UMU4 was purified through a multiplestep purification protocol (Table 2). With this purification strategy, the protease was enriched 23.28 -fold, but resulted in a lower yield $(0.45 \%)$. However, the purified protease was nearly homogeneous, as can be seen by a single band on SDS-PAGE (Figure 2A). This was also confirmed by zymogram analysis (Figure 2B). As judged by SDS-PAGE, the molecular weight of the purified protease was estimated at $45.0 \mathrm{kDa}$.

Table 2. Puriðcation proðle of the protease from the mutant UMU4 of B. subtilis S1-4.

\begin{tabular}{l|c|c|c|c|c}
\hline Purification steps & Total activity (U) & Total protein $(\mathrm{mg})$ & Specific activity (U/mg) & Purification fold & Yield (\%) \\
\hline Fermentation broth & $1,664,000$ & $19,170.51$ & 86.80 & 1.00 & 100 \\
\hline Precipitation by $\left(\mathrm{NH}_{4}\right)_{2} \mathrm{SO}_{4}$ & 46,000 & 231.17 & 198.99 & 2.30 & 2.76 \\
\hline Hydrophobic column & 17,136 & 42.28 & 405.30 & 4.67 & 1.02 \\
\hline Gel filtration & 9,516 & 4.71 & $2,020.38$ & 23.28 & 0.57 \\
\hline
\end{tabular}

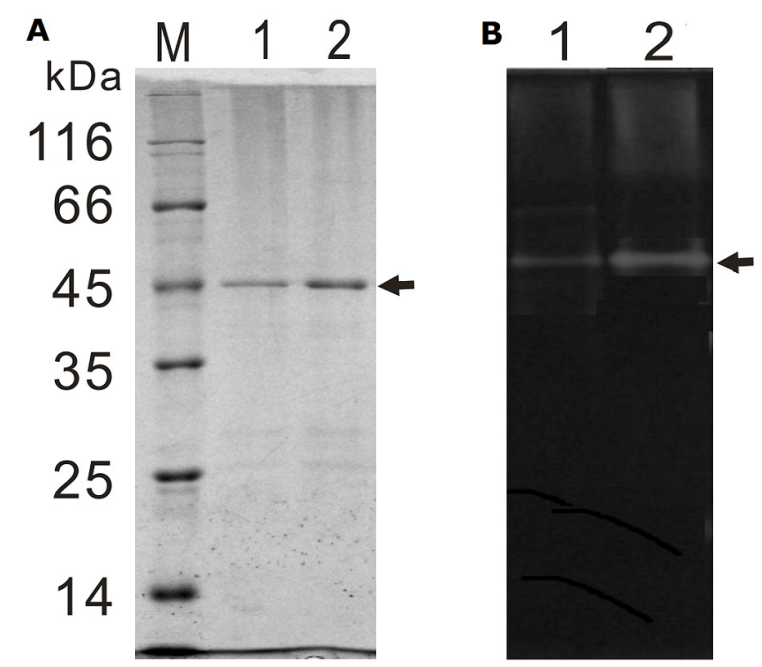

Figure 2. Analysis of SDS-PAGE (A) and zymogram (B) of the purified protease from the mutant UMU4 of Bacillus subtilis S1-4. The arrows indicate the target protein. Two and four micrograms of protease were loaded in lanes 1 and 2, respectively.

The protease purified from UMU4 showed higher hydrolytic activity towards casein over a wide range of temperatures $\left(50^{\circ}-75^{\circ} \mathrm{C}\right)$ and $\mathrm{pHs}(6-12)$ (Figure $3 \mathrm{~A}$ and $\mathrm{B}$ ), with the optimal temperature and $\mathrm{pH}$ being $65^{\circ} \mathrm{C}$ and 8.0 , respectively. The thermostability of the purified protease was determined by pre-incubating the enzyme at various temperatures for 
different times. As shown in Figure 4, the caseinolytic activity did not change remarkably at $50^{\circ} \mathrm{C}$, maintaining $>90 \%$ activity for at least $2 \mathrm{~h}$. However, an obvious loss of activity was observed with increasing the time of pre-incubation at $60^{\circ} \mathrm{C}$ or above. The half-life of thermal denaturation at $60^{\circ}, 65^{\circ}$, and $70^{\circ} \mathrm{C}$ was $72.2,21.3$, and $3.2 \mathrm{~min}$, respectively.
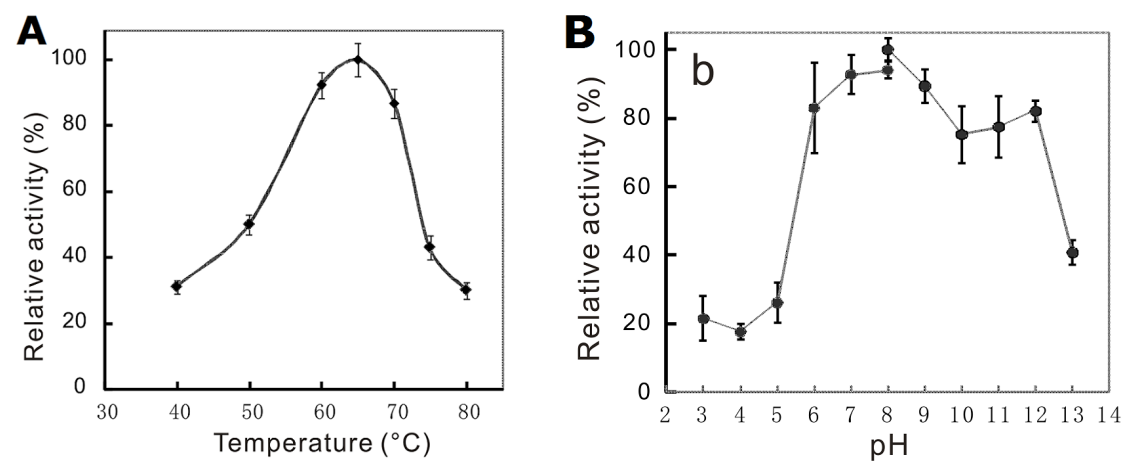

Figure 3. Effects of temperature (A) and $\mathrm{pH}(\mathbf{B})$ on the caseinolytic activity of the purified protease from the mutant UMU4 of Bacillus subtilis S1-4. The activity assay was performed at the indicated $\mathrm{pH}$ and temperatures using casein as a substrate. The data represent the average value with the standard deviation. The experiment was repeated in triplicate.

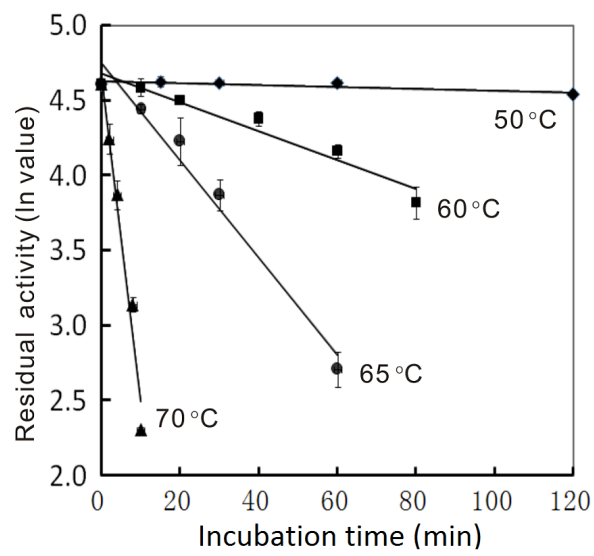

Figure 4. Thermal denaturation of the purified protease from the mutant UMU4 of Bacillus subtilis S1-4 at various temperatures in the presence of calcium ions. The thermostability analysis was performed by pre-incubating the protease at the indicated temperatures for various times in $25 \mathrm{mM}$ Tris- $\mathrm{HCl}$ buffer $(\mathrm{pH} 8.0)$ with $2 \mathrm{mM} \mathrm{Ca}^{2+}$. The residual activity was then assayed at $60^{\circ} \mathrm{C}$ with casein as substrate. The data represent the average value with the standard deviation. The experiment was repeated in triplicate.

Figure $5 \mathrm{~A}$ shows the effects of various divalent metal ions on the hydrolytic activity of the protease. In comparison with the control (without addition of any ion), the presence of 2.0 $\mathrm{mM}$ metal ions did not result in any obvious change in the hydrolytic activity of this protease, indicating that it is not sensitive to these metal ions. Interestingly, the protease activity could be enhanced by addition of some surfactants and reducing reagents to various extents (Figure 5B). $\mathrm{Na}_{2} \mathrm{SO}_{3}$ increased hydrolytic activity by about $73 \%$. However, 5 mM EGTA or PMSF 
greatly inhibited the hydrolytic activity, indicating that this protease is a serine protease. In addition, the effect of $\mathrm{NaCl}$ on hydrolytic activity was also determined. The hydrolytic activity was enhanced by less than $10 \%$ at lower concentrations of $\mathrm{NaCl}(<100 \mathrm{mM})$ and only slightly inhibited at higher concentrations of $\mathrm{NaCl}(>100 \mathrm{mM})$. When $500 \mathrm{mM} \mathrm{NaCl}$ was present in the reaction mixture, the hydrolytic activity was decreased to $86.32 \%$ in comparison with the control without $\mathrm{NaCl}$.

A

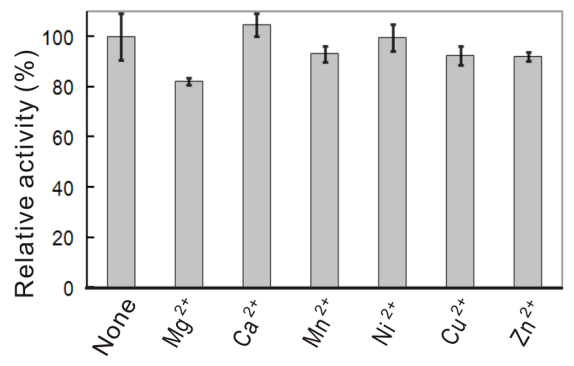

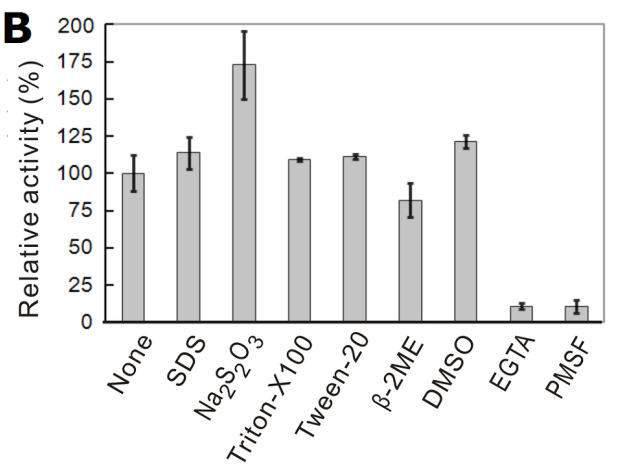

Figure 5. Effects of divalent metal ions (A) and surfactants and other chemicals (B) on the caseinolytic activity of the purified protease from the mutant UMU4 of Bacillus subtilis S1-4. The activity of the protease was assayed at $60^{\circ} \mathrm{C}$ with casein as substrate in borate- $\mathrm{NaOH}$ buffer $(\mathrm{pH} 9.6)$. The data represent the average value with the standard deviation. The experiment was repeated in triplicate.

\section{DISCUSSION}

Since proteases are important industrial enzymes, strain improvement is necessary for protease production, especially at the industrial scale. B. subtilis S1-4 strain was previously isolated from waste chicken feathers, as it was able to degrade the chicken feather efficiently (Yong et al., 2013). Keratinase or protease activity has been recognized as the key player in degradation of feather or keratin (Brandelli et al., 2010). Classic mutagenesis technology was applied to this strain in order to improve protease production. By three successive rounds of mutagenesis (UV, MNNG, and UV), a mutant UMU4 was selected with hydrolytic activity up to $464 \mathrm{U} / \mathrm{mL}$. This is a 2.5-fold increase over the activity of the parent strain S1-4 (131 $\mathrm{U} / \mathrm{mL}$ ) under the same fermentation conditions. These results indicate that UV and MNNG are efficient as the mutagenesis reagents for $B$. subtilis S1-4. UV irradiation does not always work efficiently for improving alkaline $\beta$-keratinase activity, as was seen with Brevibacillus sp strain AS-S10-II (Mukherjee et al., 2011). Mutagenesis with only UV irradiation seemed less efficient in strain improvement for protease production (Nadeem et al., 2010). The mutant strain selected after UV irradiation only showed a $44 \%$ increase in protease activity with an alkalophilic bacterial strain of B. pantotheneticus (Shikha et al., 2007). However, the protease activity in Pseudomonas sp RAJR044 was enhanced 2.5-fold by UV mutagenesis (Dutta and Banerjee, 2006). This deviation may be due to the various bacterial strains used. In general, chemical mutagenesis is more efficient for improving protease production. The keratinolytic activity was enhanced by about 2.5 -fold for the mutant KD-N2 of $B$. subtilis by MNNG mutagenesis (Cai et al., 2008). However, combination of multiple mutagenic treatments may give better results (Xia et al., 2012). The caseinolytic activity was enhanced 5-fold in the 
mutant SCU11 of B. pumilus by a combination of UV, $\gamma$-rays, and MNNG (Wang et al., 2007). In conclusion, the classic mutagenesis strategy is still efficient to increase specific protease production.

As expected, the isolate UMU4 degraded the chicken feathers more efficiently than the parent strain (Table 1), and its extracellular protease activity was about 5-fold higher than the parent strain in the feather degrading cultures. These data indicate that the increase in protease activity is a key factor in feather degradation. Further, the content of soluble proteins was increased in UMU4, although the content of free amino acids and oligopeptides were only increased by a limited amount. Accordingly, the strain improvement for the extracellular protease could serve as an alternative strategy in exploiting feather degradation since many studies have been focused on the isolation of new bacterial strains or characterization and optimal production of the keratinase or protease (Brandelli et al., 2010; KorniłłowiczKowalska and Bohacz, 2011).

An extracellular protease from the mutant UMU4 strain was purified and characterized, although both the wild-type and UMU4 strains were shown to produce several extracellular proteases by zymography analysis (data not shown). The size of the purified protease was estimated to be $45 \mathrm{kDa}$ by SDS-PAGE, which is similar to the alkaline protease KP-43 (43 $\mathrm{kDa}$ ) from Bacillus sp strain KSM-KP43 (Saeki et al., 2007). In terms of the molecular weight, this protease is different from subtilisin $\mathrm{E}(30 \mathrm{kDa})$. Furthermore, the optimal temperature for this protease to catalyze hydrolysis was higher than that of the other proteases from various Bacillus species, such as $B$. subtilis CFR3001 $\left(40^{\circ} \mathrm{C}\right)$ (Bhaskar et al., 2007), B. pumilus BA06 $\left(50^{\circ} \mathrm{C}\right)$ (Wan et al., 2009), B. proteolyticus AP MSU6 $\left(40^{\circ} \mathrm{C}\right)$ (Maruthiah et al., 2013), and $B$. subtilis GA CAS8 $\left(50^{\circ} \mathrm{C}\right)$ (Sathishkumar et al., 2015). Consequently, this protease exhibited better thermostability in comparison with the other bacterial serine proteases (Haddar et al., 2009; Maruthiah et al., 2013), as the half-life of thermal denaturation at $60^{\circ} \mathrm{C}$ approaches 72.2 min (Figure 4). Regarding $\mathrm{pH}$, the puriðed protease was active over a wide range (6.0 to 12.0) and the optimal $\mathrm{pH}$ was 8.0, which was similar with the other proteases from various Bacillus strains (Wan et al., 2009; Sathishkumar et al., 2015). However, this protease was less sensitive to the metal ions tested in this study. Usually, heavy metal ions, like $\mathrm{Cu}^{2+}$ and $\mathrm{Hg}^{2+}$, lead to moderate inhibition of the hydrolytic activity of some bacterial serine proteases. For example, the protease from $B$. subtilis GA CAS8 was inhibited by $\mathrm{Cu}^{2+}$ and $\mathrm{Zn}^{2+}$ (Sathishkumar et al., 2015). In contrast, the hydrolytic activity of the protease from B. subtilis AP-MSU6 was stimulated by $\mathrm{Cu}^{2+}$ and $\mathrm{Hg}^{2+}$ (Maruthiah et al., 2013).

As shown in Figure 5, the hydrolytic activity was increased when surfactants like Triton X-100 and Tween-20 were added to the hydrolytic reaction, which was similar to other proteases from the different Bacillus species (Had-Alij et al., 2007; Haddar et al., 2009; Shah et al., 2010). Noticeably, $\mathrm{Na}_{2} \mathrm{SO}_{3}$ resulted in a $73 \%$ increase in the hydrolytic activity for this protease in comparison with the control (without addition of the additive). $\mathrm{Na}_{2} \mathrm{SO}_{3}$ has been previously reported to enhance feather degradation (Yong et al., 2013). In terms of chemical properties, $\mathrm{Na}_{2} \mathrm{SO}_{3}$ may provide reducing power that would help the substrate unfold to be accessible to the enzyme.

In conclusion, a high protease-producing mutant UMU4 was selected from B. subtilis S1-4 by three successive rounds of mutagenesis using UV irradiation and MNNG treatment. Feather degradation was enhanced in this mutant, as can be seen by the increase in soluble protein content, which suggests that strain improvement for the production of protease could be an alternative strategy in feather degradation. The main extracellular protease produced 
by UMU4 was purified and characterized, indicating this protease is a typical serine protease with higher than usual optimal temperature and good thermostability in caseinolytic activity. These data suggest that the mutant UMU4 and its serine protease could be of use in various industries.

\section{Conflicts of interest}

The authors declare no conflict of interest.

\section{ACKNOWLEDGMENTS}

to $\mathrm{H}$. Feng.

Research supported by the National Natural Science Foundation of China (\#31171204)

\section{REFERENCES}

Bhaskar N, Sudeepa ES, Rashmi HN and Tamil Selvi A (2007). Partial purification and characterization of protease of Bacillus proteolyticus CFR3001 isolated from fish processing waste and its antibacterial activities. Bioresour. Technol. 98: 2758-2764. http://dx.doi.org/10.1016/j.biortech.2006.09.033

Brandelli A, Daroit DJ and Riffel A (2010). Biochemical features of microbial keratinases and their production and applications. Appl. Microbiol. Biotechnol. 85: 1735-1750. http://dx.doi.org/10.1007/s00253-009-2398-5

Bryan PN (2000). Protein engineering of subtilisin. Biochim. Biophys. Acta 1543: 203-222. http://dx.doi.org/10.1016/ $\underline{\mathrm{S} 0167-4838(00) 00235-1}$

Cai CG, Lou BG and Zheng XD (2008). Keratinase production and keratin degradation by a mutant strain of Bacillus subtilis. J. Zhejiang Univ. Sci. B 9: 60-67. http://dx.doi.org/10.1631/jzus.B061620

Cedrola SM, de Melo AC, Mazotto AM, Lins U, et al. (2012). Keratinases and sulfide from Bacillus subtilis SLC to recycle feather waste. World J. Microbiol. Biotechnol. 28: 1259-1269. http://dx.doi.org/10.1007/s11274-011-0930-0

Dutta JR and Banerjee R (2006). Isolation and characterization of a newly isolated Pseudomonas mutant for protease production. Braz. Arch. Biol. Technol. 49: 37-47. http://dx.doi.org/10.1590/S1516-89132006000100005

Gupta R, Beg QK and Lorenz P (2002). Bacterial alkaline proteases: molecular approaches and industrial applications. Appl. Microbiol. Biotechnol. 59: 15-32. http://dx.doi.org/10.1007/s00253-002-0975-y

Had-Alij N, Agrebi R, Ghorbel-Frikha B, Sellami-Kamoun A, et al. (2007). Biochemical and molecular characterization of a detergent stable alkaline serine-protease from a newly isolated Bacillus licheniformis NH1. Enzyme Microb. Technol. 40: 515-523. http://dx.doi.org/10.1016/j.enzmictec.2006.05.007

Haddar A, Bougatef A, Agrebi R, Sellami-Kamoun A, et al. (2009). A novel surfactant-stable alkaline serine-protease from a newly isolated Bacillus mojavensis A21. Puriðcation and characterization. Process Biochem. 44: 29-35. http:// dx.doi.org/10.1016/j.procbio.2008.09.003

Korniłłowicz-Kowalska T and Bohacz J (2011). Biodegradation of keratin waste: Theory and practical aspects. Waste Manag. 31: 1689-1701. http://dx.doi.org/10.1016/j.wasman.2011.03.024

Kumar CG and Takagi H (1999). Microbial alkaline proteases: from a bioindustrial viewpoint. Biotechnol. Adv. 17: 561594. http://dx.doi.org/10.1016/S0734-9750(99)00027-0

Li XY, Zhang JL and Zhu SW (2011). Improved thermostable $\alpha$-amylase activity of Bacillus amyloliquefaciens by lowenergy ion implantation. Genet. Mol. Res. 10: 2181-2189. http://dx.doi.org/10.4238/vol10-3gmr1081

Maruthiah T, Esakkiraj P, Prabakaran G, Palavesam A, et al. (2013). Puriðcation and characterization of moderately halophilic alkaline serine protease from marine Bacillus subtilis AP-MSU6. Biocatal. Agric. Biotechnol. 2: 116-119.

Mukherjee AK, Rai SK and Bordoloi NK (2011). Biodegradation of waste chicken-feathers by an alkaline $\beta$-keratinase (Mukartinase) purified from a mutant Brevibacillus sp. strain AS-S10-II. Int. Biodeterior. Biodegradation 65: 12291237. http://dx.doi.org/10.1016/j.ibiod.2011.09.007

Nadeem M, Qazi JI and Baij S (2012). Enhanced production of alkaline protease by mutant of Bacillus lichenifromis N-2 for dehairing. Braz. Arch. Biol. Technol. 53: 1015-1025. http://dx.doi.org/10.1590/S1516-89132010000500003

Parekh S, Vinci VA and Strobel RJ (2000). Improvement of microbial strains and fermentation processes. Appl. Microbiol. Biotechnol. 54: 287-301. http://dx.doi.org/10.1007/s002530000403 
Polgár L (2005). The catalytic triad of serine peptidases. Cell. Mol. Life Sci. 62: 2161-2172. http://dx.doi.org/10.1007/ $\underline{\mathrm{s} 00018-005-5160-\mathrm{x}}$

Rao MB, Tanksale AM, Ghatge MS and Deshpande VV (1998). Molecular and biotechnological aspects of microbial proteases. Microbiol. Mol. Biol. Rev. 62: 597-635.

Rowlands RT (1984). Industrial stain improvement: mutagenesis and random screening procedures. Enzyme Microb. Technol. 6: 3-10. http://dx.doi.org/10.1016/0141-0229(84)90070-X

Saeki K, Ozaki K, Kobayashi T and Ito S (2007). Detergent alkaline proteases: enzymatic properties, genes, and crystal structures. J. Biosci. Bioeng. 103: 501-508. http://dx.doi.org/10.1263/jbb.103.501

Sathishkumar R, Ananthan G and Arun J (2015). Production, purification and characterization of alkaline protease by ascidian associated Bacillus subtilis GA CAS8 using agricultural wastes. Biocatal. Agric. Biotech. 4: 214-220.

Shah K, Mody K, Keshri J and Jha B (2010). Puriðcation and characterization of a solvent, detergent and oxidizing agent tolerant protease from Bacillus cereus isolated from the Gulf of Khambhat. J. Mol. Catal., B Enzym. 67: 85-91. http:// dx.doi.org/10.1016/j.molcatb.2010.07.010

Shikha AS, Sharan A and Darmwal NS (2007). Improved production of alkaline protease from a mutant of alkalophilic Bacillus pantotheneticus using molasses as a substrate. Bioresour. Technol. 98: 881-885. http://dx.doi.org/10.1016/j. biortech.2006.03.023

Vinci VA and Byng G (1999). Strain improvement by non-recombinant methods. In Manual of Industrial Microbiology and Biotechnology (Demain AL, Davis JE eds.), ASM, Washington, DC, USA, pgs. 103-113.

Wan MY, Wang HY, Zhang YZ and Feng H (2009). Substrate specificity and thermostability of the dehairing alkaline protease from Bacillus pumilus. Appl. Biochem. Biotechnol. 159: 394-403. http://dx.doi.org/10.1007/s12010-008$\underline{8497-4}$

Wang HY, Liu DM, Liu Y, Cheng CF, et al. (2007). Screening and mutagenesis of a novel Bacillus pumilus strain producing alkaline protease for dehairing. Lett. Appl. Microbiol. 44: 1-6. http://dx.doi.org/10.1111/j.1472-765X.2006.02039.x

Xia W, Li H, Wang X, Zhang G, et al. (2012). Mutagenesis of alkaline protease-producing marine strains and enzymatic properties. Agric. Biotechnol. 1: 32-34.

Yong B, Yang BQ and Feng H (2013). Efficient degradation of raw chicken feather into soluble peptides and free amino acids by a newly isolated Bacillus subtilis S1-4. Res. J. Biotechnol. 8: 48-55.

Zamost BL, Brantley QI, Elm DD and Beck CM (1990). Production and characterization of a thermostable protease produced by an aporogenous mutant of Bacillus stearothermophilus. J. Ind. Microbiol. 5: 303-312. http://dx.doi. org/10.1007/BF01578205 